\title{
Les sites fortifiés de hauteur protohistoriques du
} Calvados

$\mathrm{n}^{\circ} 3382$

Hervé Duval et Pierre Giraud

\section{(2) OpenEdition \\ Journals}

Édition électronique

URL : http://journals.openedition.org/adlfi/17035

ISSN : 2114-0502

Éditeur

Ministère de la culture

Référence électronique

Hervé Duval et Pierre Giraud, «Les sites fortifiés de hauteur protohistoriques du Calvados », ADLFI.

Archéologie de la France - Informations [En ligne], Basse-Normandie, mis en ligne le 17 mars 2016,

consulté le 19 avril 2019. URL : http://journals.openedition.org/adlfi/17035

Ce document a été généré automatiquement le 19 avril 2019

(c) Ministère de la Culture et de la Communication, CNRS 


\title{
Les sites fortifiés de hauteur protohistoriques du Calvados
}

$n^{\circ} 3382$

\author{
Hervé Duval et Pierre Giraud
}

Lien Atlas (MCC) :

1 Quatre types de travaux ont été réalisés dans le cadre de cette prospection thématique en 2013. Le premier a consisté à continuer la mise en place d'un SIG développé sous le logiciel MapInfo ${ }^{\circledR}$ Professional. L'objectif de ce système d'information est de réaliser un outil de cartographie, d'analyse et de prospection sur les sites de hauteur de ce département. Le second type de travaux correspond à des prospections sur certains sites potentiels : repérages, photographies et relevés topographiques (GPS). Le troisième a été de réaliser des clichés par cerf-volant (réalisation Arnaud Poirier) et le dernier est la réalisation d'une opération de sondages sur le site de la Hoguette à Moult par Hervé Duval.

2 La campagne de photographies par cerf-volant réalisée fin juin et début juillet 2013 a permis de localiser des vestiges inédits sur une des parcelles de cette commune. Il s'agit potentiellement d'une voirie à fossés bordiers et de deux enclos quadrangulaires de petites dimensions. Ces découvertes sont encourageantes car elles permettent de conforter l'hypothèse d'une implantation gauloise importante sur ce rebord de plateau protégé naturellement par des falaises.

3 L'opération de sondages sur le site de Moult, la Hoguette, avait plusieurs objectifs. Il s'agissait d'une part de documenter l'ouvrage défensif et d'autre part de déterminer la ou les phase(s) d'occupation(s) de ce site. Les quatre tranchées réalisées au sein du site ont permis de respecter les attentes et de fournir des informations sur un site qui n'avait, jusque-là, jamais fait l'objet de fouille archéologique. La fortification de barrage de près de $4 \mathrm{~m}$ de hauteur, a fait l'objet d'une tranchée qui l'a coupé en son milieu, permettant ainsi d'obtenir la séquence stratigraphique la plus complète possible. Si plusieurs étapes de construction ont pu être identifiées, il semble qu'elles soient toutes attribuables à la 
période de La Tène finale, comme cela avait été envisagé par Mortimer Wheeler. Il est donc désormais possible d'affirmer que cette ligne de défense s'apparente au type «talus massif » et, dans son cas, d'une fortification de type Fécamp, puisqu'un important fossé précède la fortification. Par ailleurs, les niveaux d'effondrements successifs du talus massif ont permis une très bonne conservation des vestiges situés à l'arrière de la fortification (côté sud-ouest). Des vestiges archéologiques témoignent d'une occupation interne de l'éperon barré durant La Tène finale. En effet, un des sondages a permis de mettre au jour les restes d'une chaussée ainsi qu'un niveau d'occupation présentant de nombreux rejets (céramique, faune, objets en fer, monnaie) parmi lesquels se trouvait du mobilier d'importation (amphore et céramique de type Besançon). Le mobilier recueilli permet d'établir un parallèle avec celui découvert sur l'éperon barré du Mont Cavalier à Commes, ainsi que sur l'oppidum du Castellier à Saint-Désir/Saint-Pierre-des-Ifs. À la vue des vestiges découverts, il semble que l'organisation interne du site de la Hoguette se soit organisée autour de voies. Les très bons niveaux de conservation des vestiges et de la stratigraphie ont également permis de repérer d'autres phases d'occupation, dont un fossé rattachable à l'âge du Bronze ou au premier âge du Fer. Du mobilier résiduel (éclats et silex taillés) laissait également entrevoir une occupation durant le Néolithique; une situation connue pour d'autres petits éperons de la région.

INDEX

Index chronologique : Protohistoire

Mots-clés : voirie, enclos, fortification, céramique, silex

operation Prospection thématique (PRT)

Index géographique : Basse-Normandie, Calvados (14)

\section{AUTEURS}

HERVÉ DUVAL

CG 14 